\title{
PRELIMINARY PHYTOCHEMICAL SCREENING AND IN VITRO ANTIMICROBIAL ACTIVITY OF ETHANOLIC EXTRACT OF WHOLE AERIAL PART OF THE HERB LEUCAS PLUKENETII SPRENG (FAMILY-LAMINACEAE)
}

\author{
UTTAM BORAH*, BISWAJIT DASH, SUVAKANTA DASH, JUMAN DEKA, LAWRENCE KALITA \\ ${ }^{1}$ Girijananda Chowdhury Institute of Pharmaceutical Science, Azara, Guwahati 781017 \\ Email: borahuttam@yahoo.in
}

Received: 28 Dec 2016, Revised and Accepted: 27 Mar 2017

\begin{abstract}
Objective: To evaluate the antimicrobial activity of ethanolic extract of Leucas Plukenetii Spreng (family-laminaceae) in conjugation with phytochemical analysis.

Methods: The ethanolic extract of whole aerial parts of the herb Leucas Plukenetiispreng (family-laminaceae) was prepared and analysed for phytochemical constituents using standard methods. The antimicrobial activity of the plant extract was examined against 2 bacterial strains among one is gram positive and other is gram negative and 2 fungal strains using agar well diffusion method.
\end{abstract}

Results: The present investigation shows the phytochemical analysis, antimicrobial activity of the ethanolic extract of the plant Leucas Plukenetii Spreng. Various phytochemical analyses revealed the presence of alkaloids, saponin, flavonoids, carbohydrates, glycosides, Steroids, proteins and amino acids and tannins. The antimicrobial activity of the ethanolic extract of the plant showed significant result against all the of the test organisms.

Conclusion: The present study concluded that ethanolic extract of whole aerial parts of the Leucas Plukenetii Spreng contains the high presence of phytochemicals. The ethnaolic extract of the plant was found to possess promising antimicrobial activity when compared with the standards.

Keywords: Leucas Plukenetii, Antimicrobial, Zone of Inhibition, Agar disc diffusion method

(C) 2017 The Authors. Published by Innovare Academic Sciences Pvt Ltd. This is an open access article under the CC BY license (http://creativecommons.org/licenses/by/4.0/)

DOI: http://dx.doi.org/10.22159/ijcpr.2017v9i3.19598

\section{INTRODUCTION}

Since back then plants have produced a various range of bioactive molecules, creating them the upscale supply of different types of medicines. Today, most of the medicine are obtained from natural sources or semi-artificial derivatives of natural products utilized in the standard systems of medicine [1].

Thusly, it is an intelligent approach in medication disclosure to screen customary common items. Around $20 \%$ of the plants found on the planet have been submitted to the pharmaceutical or organic test and a manageable number of new anti-infection agents presented in the market are gotten from regular or semimanufactured assets [2].

The cure as of now being used to treat irresistible illness are of concern since medication wellbeing remains a huge worldwide issue. The vast majority of the engineered drugs cause side effects and furthermore, the majority of the microorganisms created resistance against the manufactured medications [3]. To defeat this deterrent, antimicrobial mixes from potential plants ought to be investigated. The medications from plants sources are less dangerous, symptoms are insufficient and furthermore financially savvy. These are powerful in the treatment of irresistible ailments while at the same time moderating a hefty portion of the reactions that are regularly connected with engineered antimicrobials [4].

World Health Organization (WHO) reasoned that restorative plants would be the best source to acquire an assortment of medications [5]. Many plant species are utilized by numerous ethnic gatherings for the treatment of different afflictions extending from minor contaminations to the looseness of the bowels, skin infections, asthma, malaria and a swarm of different signs [6]. Natural based antimicrobials speak to a tremendous undiscovered wellspring of pharmaceuticals and further investigation of plant antimicrobials is the need of great importance. Antimicrobials of plant starting point have huge helpful potential. Restorative plant-determined antimicrobials have a long history of giving the genuinely necessary novel therapeutics and treatment [7].

The therapeutic plants continually collaborate with the quickly changing and possibly harming outside ecological variables. In spite of the fact that living beings without versatility, plants have advanced expand elective safeguard methodologies, which include a huge assortment of compound metabolites as devices to conquer stretch conditions. The capacity of plants to complete combinatorial chemistry by mixing, coordinating and developing the quality items required for secondary metabolite biosynthetic pathways, makes a boundless pool of chemicals, which people have abused to their advantage. Consequently, the utilization of plants by people in both conventional and present day therapeutic frameworks, in this manner, to a great extent utilize this standard [8].

Those plants having restorative significance are discovering their way into pharmaceuticals, beautifying agents, and Nutraceuticals. In pharmaceutical field therapeutic plants are for the most part utilized for the largest scope of substances present in plants which have been utilized to regard incessant and irresistible ailments. Much sooner than humankind found the presence of organisms, the possibility that specific plants had recuperating potential, without a doubt, that they contained what we would right now portray as antimicrobial standards, was all around acknowledged. Since vestige, man has utilized plants to treat normal irresistible infections and some of these conventional meds are as yet included as a major aspect of the chronic treatment of different illness [9].

Multidrug resistance dependably makes remedial inadequacy. The quantity of multi-medication resistant microbial strains and the presence of strains with lessened vulnerability to antibiotics are ceaselessly expanding. The development has been credited to the unpredictable utilization of expansive range anti-infection agents, an immunosuppressive operator, intravenous catheters, organ transmanor and continuous scourges of HIV disease. Aside from this issue, antibiotics are some of the time related to antagonistic consequences for the host, including extreme touchiness, insusceptible concealment, 
and hypersensitive responses. This circumstance constrained researchers to look for new antimicrobial substances. It is given the disturbing occurrence of anti-infection resistance in microorganisms of medicinal significance, there is a steady requirement for new and viable restorative specialists. Along these lines, there is a need to create selective antimicrobial medications for the treatment of irresistible maladies from restorative plants [10].

Leucas Plukenetii belonging to the family laminaceaedevelops as a weed on Badlands and roadsides all over India. Literature Survey reveals that it had been utilized by the tribes in different parts of Asia and Africa for. Widely employed different species, their parts and mode of application/administration in different irresistible condition locally [11].

So he points of this present study is to recognize the phytochemical of Leucas plukenetii and to decide the antimicrobial impacts of the whole aerial part extract on E. coli, S. aureus, Candida albicans and Trichophyton rubrum.

\section{MATERIALS AND METHODS}

\section{Collection of plant materials}

Leucas Plukenetii Spring was gathered from Narayanpur, Lakhimpur, Assam, India. The plant specimen was authenticated by Dr. G. C. Sarma, Curator, Department of Botany, Gauhati University, Guwahati, Assam. The voucher specimen has been stored in the Herbarium of the Department of Botany, Gauhati University with voucher no Acc. No-18202 dated 26-09-2016 for future reference.

\section{Chemicals and reagents}

Petroleum Ether(PE), Ethanol (ET), dimethyl sulfoxide(DMSO), hydrochloric acid, Dragondorff reagent, Mayer's reagent, Wagner's reagent, Benedict's reagent, sulphuric acid, lead acetate, Molisch's reagent, Fehling solution A and B, sodium citrate, copper sulphate, ferric chloride, sodium hydroxide, glacial acetic acid, benzene, chloroform, ammonia, nitric acid, potassium nitrite,gelatine, Beef extract, Peptone and agar. All the chemicals and solvents used were of standard analytical grades.

\section{Preparation of the plant extract}

The whole crisp plant materials were collected washed, shade-dried and then kept at tray drier at $37^{\circ} \mathrm{C}$ for $48 \mathrm{~h}$. The dried plant materials were grinded to a fine powder utilizing an electric grinder. The dried and powdered plant material was defatted by using Petroleum Ether and then extracted with Ethanol in the order of their increasing polarity by maceration process until it got to be distinctly dreary as indicated by the standard techniques [14]. The ethanolic extract was concentrated by using rotary vacuum evaporator and put away in the refrigerator for further investigation.

The extract acquired was weighed and the the rate yield was figured as far as the dried weight of the plant material utilizing the equation:

$\%$ Yield = (Dry weight of the extract/Dry weight of leaf sample $)$ $\mathrm{x} 100$.

The shading and consistency of the concentrate were additionally noted.

\section{Phytochemical screening}

The plant extract was investigated for the nearness of alkaloids, saponin, flavonoids, phenol, carbohydrates, proteins and amino acids, cardiac glycosides, steroids, anthraquinone and terpenoids using the the standard strategies.

\section{Detection of alkaloids}

The extract was dissolved in dilute Hydrochloric acid and filtered

a) Mayer's Test: Filtrates were treated with Mayer's reagent (Potassium Mercuric Iodide). Formation of a yellow coloured precipitate indicates the presence of alkaloids.

b) Wagner's Test: Filtrates were treated with Wagner's reagent (Iodine in Potassium Iodide). Formation of brown/reddish precipitate indicates the presence of alkaloids. c) Dragendroff's Test: Filtrates were treated with Dragendroff's reagent (solution of Potassium Bismuth Iodide). Formation of red precipitate indicates the presence of alkaloids.

\section{Detection of saponins}

Foam Test: 0.5 gm of the extract was shaken with $2 \mathrm{ml}$ of water. If foam produced persists for ten minutes it indicates the presence of saponins.

\section{Detection of flavonoids}

Lead acetate Test: Extract was treated with few drops of lead acetate solution. Formation of yellow colour precipitate indicates the presence of flavonoids.

\section{Detection of carbohydrates}

The extract was dissolved individually in $5 \mathrm{ml}$ distilled water and filtered. The filtrates were used to test for the presence of carbohydrates.

a) Molisch's Test: Filtrates were treated with 2 drops of alcoholic $\alpha$ naphthol solution in a test tube. Formation of the violet ring at the junction indicates the presence of Carbohydrates.

b) Benedict's Test: Filtrates were treated with Benedict's reagent and heated gently. Orange red precipitate indicates the presence of reducing sugars.

c) Fehling's Test: Filtrates were hydrolysed with dil. $\mathrm{HCl}$, neutralized with alkali and heated with Fehling's A and B solutions. Formation of red precipitate indicates the presence of reducing sugars.

\section{Detection of glycosides}

The extract was hydrolysed with dil. $\mathrm{HCl}$, and then subjected to test for glycosides.

\section{Modified borntrager's test}

The extract was treated with Ferric Chloride solution and immersed in boiling water for about $5 \mathrm{~min}$. The mixture was cooled and extracted with equal volumes of benzene. The benzene layer was separated and treated with ammonia solution. Formation of rosepink colour in the ammonical layer indicates the presence of anthranol glycosides

\section{Detection of phytosterols}

Salkowski's Test: Extract was treated with chloroform and filtered. The filtrates were treated with few drops of Conc. Sulphuric acid, shaken and allowed to stand. The appearance of golden yellow colour indicates the presence of triterpene.

\section{Detection of proteins and amino acids}

Xanthoproteic Test: The Extract was treated with few drops of conc. Nitric acid. Formation of yellow colour indicates the presence of proteins.

\section{Detection of tannins}

Gelatin Test: To the extract, 1\% gelatin solution containing sodium chloride was added. Formation of white precipitate indicates the presence of tannins [12].

\section{Microbial strains}

Three bacterial strains [Staphyllococcus aureus (ATCC 25923), Escherichia coli (ATCC 25922)and two fungi [Candida albicans (ATCC 10231), and Trichophyton rubrum (ATCC 28188)] were used. Stains were obtained from Girijananda Chowdhury Institute of Pharmaceutical Science, Azara, Guwahati.

\section{Antibacterial activity}

The antimicrobial action of the plant extract was measured by agarwell diffusion technique as described in NCCLS,1993[13]. Petri plates containing $20 \mathrm{ml}$ nutrient agar medium was seeded with bacterial strains. Wells of approximately $10 \mathrm{~mm}$ was bored using a well cutter. Plant extract was prepared in DMSO (stock: $1 \mathrm{mg} / \mathrm{ml}$ DMSO). The plant extract of 25,50 , and $100 \mu$ l concentrations were added. Ciprofloxacin $(20 \mu \mathrm{l})$ and DMSO $(100 \mu \mathrm{l})$ were used as positive and negative controls respectively. The plates were then 
incubated at $37{ }^{\circ} \mathrm{C}$ for $24 \mathrm{~h}$. The antimicrobials present in the plant extract are allowed to diffuse out into the medium and interact with the test organisms in the freshly seeded plate. The diameter of the zone of inhibitions was measured in millimetres after $24 \mathrm{~h}$.

\section{Antifungal activity}

The potato dextrose agar plates were prepared and inoculated with a fungal culture. Wells of approximately $10 \mathrm{~mm}$ was bored using a well cutter and samples of different concentration were added. The zone of inhibition was measured in millimetres after overnight incubation and compared with that of standard antifungal (Fluconazole) $(10 \mu \mathrm{l})$ which was used as positive control and DMSO $(10 \%)$ as the negative control [14].

\section{RESULTS}

The present investigation shows the phytochemical analysis, antimicrobial activity of the ethanolic extract of the plant Leucas
Plukenetii Spreng. The yield \% of the extraction of ethanol was $3.82 \%$. It was a light green solid powder (ET) in appearance.

\section{Phytochemical analysis}

Different phytochemical investigations with the ethanolic plant extract were demonstrated the nearness of alkaloids, saponin, flavonoids, starches, glycosides, Steroids, proteins and amino acids and tannins (table 1).

\section{Antimicrobial activity}

Plant extract is generally rich in antimicrobial compounds. The in vitro antimicrobial activity of the ethanoic extract of Leucas Plukenetii Spreng under different concentration with the standard are appeared at table 2 .

The ethanolic extract of whole aerial parts of the plant showed antimicrobial activity against a large portion of the test organisms.

Table 1: Phytochemical screening of ethanolic (ET) extract of whole aerials parts of Leucas Plukenetii Spreng

\begin{tabular}{llll}
\hline S. No. & Phytochemicaltest & Reagentsused (testperformed) & Observation \\
\hline 1 & Alkaloidstest & Mayer's test & Result \\
& & Wagner's test & Reamy white precipitate \\
& & Dragendoroff's test & Reddish brown colour yellow precipitate \\
& & Foam test & Frange brown precipitate \\
2 & Saponin test & LeadAcetate test & Yellowprecipitate \\
3 & Flavonoidtest & Molisch'stest & Formation of violetring \\
4 & Carbohydrate test & Benedict's test & Formation of orange red precipitate \\
& & Fehling's test & Formation of red precipitate \\
5 & Glycosides test & Modified Borntrager's test & Formation of pink colour \\
6 & Steroid test & Salkowski's test & Formation of green colour \\
7 & ProteinsandAmino Acids & Xanthoproteic test & Formation of yellow colour \\
8 & Tanninstest & Gelatin test & Formation of green colour \\
\hline
\end{tabular}

+sign indicatespresence and-sign indicatesabsence.

Table 2: Antimicrobial activity ofLeucas Plukenetii Spreng extract usingdiscdiffusionassay

\begin{tabular}{|c|c|c|c|c|}
\hline \multirow[t]{2}{*}{ Name of the compounds and their concentration } & \multicolumn{2}{|c|}{$\begin{array}{l}\text { Antibacterial activity diameter of } \\
\text { inhibition zone ( }(\mathrm{mm})\end{array}$} & \multicolumn{2}{|c|}{$\begin{array}{l}\text { Antifungal Activitydiameter of } \\
\text { inhibition zone ( } \mathrm{mm})\end{array}$} \\
\hline & Staphyllococcusaureus & Escherichiacoli & C. albicans & Trichophyton rubrum \\
\hline StandardCiprofloxacin $(20 \mu \mathrm{l})$ & 45 & 43 & $-\cdots$ & $-\cdots$ \\
\hline StandardFluconazole $(20 \mu \mathrm{l})$ & ----- & ---- & 34.32 & 33.32 \\
\hline Plant Extract $(25 \mu l)$ & 14.3 & 12.1 & 13.2 & 11.2 \\
\hline Plant Extract $(50 \mu l)$ & 22.33 & 15.33 & 16.95 & 13.95 \\
\hline Plant Extract $(100 \mu l)$ & $25.26 *$ & $19.26 *$ & $20.2^{*}$ & $15.2 *$ \\
\hline
\end{tabular}

*significant activity

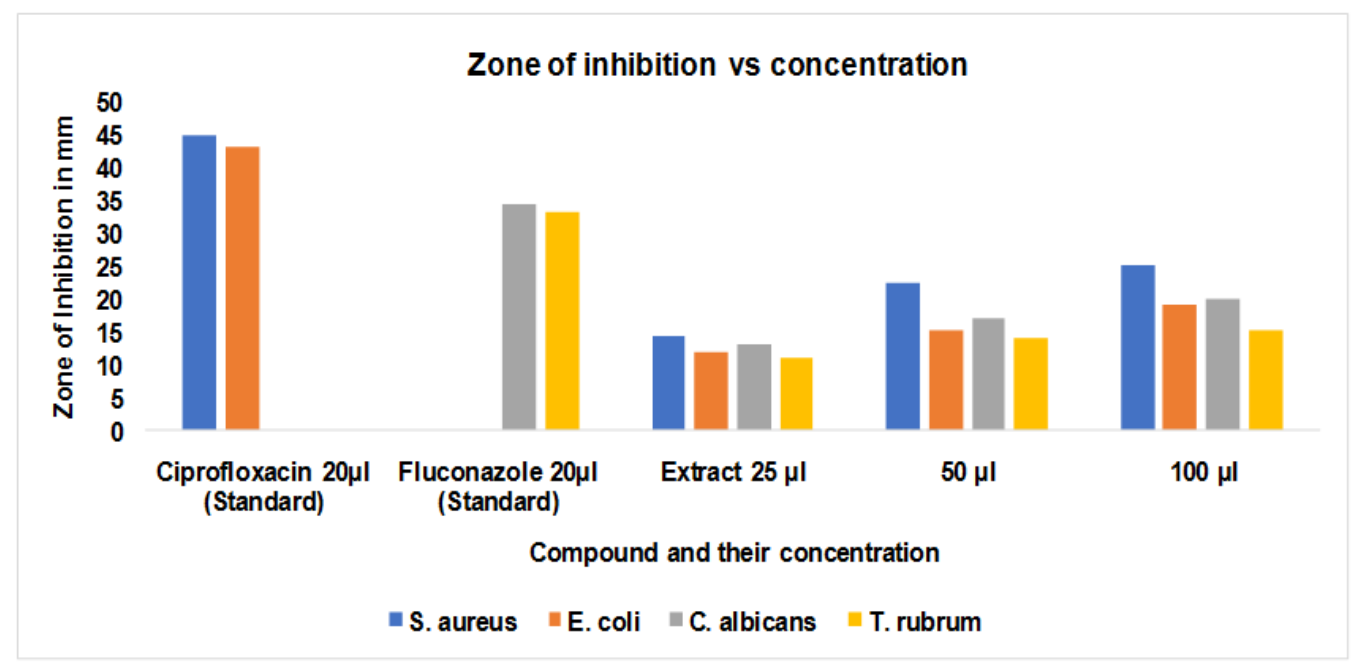

Fig. 1: Zone of inhibition vs concentration 


\section{DISCUSSION}

The antimicrobial activity of whole aerial parts of plant has been assessed. Phyto-constituents exhibit in plants to be specific alkaloids, flavonoids, tannins and triterpenoids are delivering an energizing open door for expansion of modern therapies against an extensive variety of microorganisms. In the present study, a variety of Gram-positive, Gram-negative bacteria, and fungal strains were chosen for screening antimicrobial impact of the extract tosee antimicrobial spectrum. The consequences of this study showed that the ethanolic extract of the plant Leucas Plukenetii Spreng was exceptionally successful towards the majority of the Gram-positive microbes, Gram-negative microscopic organisms, and fungal strains in agar well diffusion strategy.

Plant phytochemical constituents, for example, tannins, alkaloids, flavonoids, phenolic compounds and several other aromatic compounds are secondary metabolites of plantthat fill in as a barrier component against predation by numerous microorganisms.

The exhibit of antimicrobial activity against both Gram-positive and Gram-negativebacteria and on various fungal strains might be demonstrative of the presence of broad spectrum antibiotic compounds in the extract which is clearly shown in fig. 1 . The $100 \mu \mathrm{g} / \mathrm{ml}$ concentration of extract having the most affecting antimicrobial activity.

\section{CONCLUSION}

Plant has long been a very vital source of drug and many plants have been screened on the off chance that they contain mixes with helpful movement. In this manner, it is essential to assess the antimicrobial activity of Leucas Plukenetii Spreng.

In this study, the antibacterial activity of the aerial parts of Leucas Plukenetii Spreng was evaluated by using disk diffusion method. The microorganisms chosen to be studied were Gram positive, S. aureus and Gram negative E. coli and fungus like C. albicans, and T. rubrum. These micro-organism were chosen to be studied as they are imperative pathogens and furthermore because of quickly created anti-microbial resistance.

The present study finished up ethanolic extract of Leucas Plukenetii Spreng showed the presence of various phytochemicals of which alkaloids, saponin, flavonoids, carbohydrates, glycosides, Steroids, proteins and amino acids and tannins.

The present study revealed huge antimicrobial activity of the plant extract when compared with standards. Since the base inhibitory grouping of the plant concentrate was under $100 \mu \mathrm{g} / \mathrm{ml}$, the plant was considered to have a decent antimicrobial action.

Be that as it may, additionally studies are required to toss light on the biological activity of Leucas Plukenetii Spreng and its bioactive compounds against various diseases.

\section{ACKNOWLEDGMENT}

The authors acknowledged the Head of Department, Guwahati university for authenticate the plant and Principal and Department of Microbiology, Girijananda Chowdhury Institute of Pharmaceutical Science,Azara, Guwahati for conveying this exploration work.

\section{CONFLICT OF INTERESTS}

Declare none

\section{REFERENCES}

1. Sukanya SL, Sudisha J, Hariprasad P, Niranjana SR, Prakash HS, Fathima SK. Antimicrobial activity of leaf extracts of Indian medicinal plants against clinical and phytopathogenic bacteria. Afr J Biol 2009;8:6677-82.

2. Mothana RA, Lindequist U. Antimicrobial activity of some medicinal plants of the island Soqotra. J Ethnopharmacol 2005;96:177-81.

3. Chanda S, Rakholiya K. Combination therapy: synergism between natural plant extracts and antibiotics against infectious diseases. Microbiol Book Series; 2011. p. 520-9.

4. Harishchandra MR, Rajan PR, Singh Satyendrakumar RP. Study of krimighna effect of nimba (Azadiracta indica A. Juss.) patra as rakshoghna dhoopan by culture and sensitivity method W. S. R. to pyogenic bacteria. Int Res J Pharm 2012;3:142-6.

5. Nascimento GF, Lacatelli J, Freitas PC, Silva GL. Antibacterial activity of plant extracts and phytochemicals on antibioticresistant bacteria. Brazilian J Microbiol 2000;31:886-91.

6. Dahanukar SA, Kulkarni RA, Rege NN. Pharmacology of medicinal plants and natural products. Indian J Pharmacol 2000;32:81-118.

7. Silva MSP, Brandao DO, Chaves TP, Filho ALNF, Costa EMDB, Santos VL, et al. Study bioprospecting of medicinal plant extracts of the semiarid northeast: contribution to the control of oral microorganisms. J Evidence-Based Complementary Altern Med 2012;2012:1-6.

8. Ncube B, Finnie JF, Staden JV. In vitro antimicrobial synergism within plant extract combinations from three South African medicinal bulbs. J Ethnopharmacol 2012;139:81-9.

9. Hemalatha M, Thirumalai T, Saranya R, Elumalai EK, David E. A review on antimicrobial efficacy of some traditional medicinal plants in Tamilnadu. J Acute Disease 2013;2:99-105.

10. Gowrish A, Vagdevi HM, Rajashekar H. Phytochemical screening and antimicrobial activity of Leucas marrubioides desf. root extracts. Int J Pharm Pharm Sci 2016;8:209-10.

11. Chouhan HS, Singh SK. A review of plants of genus Leucas. J Pharmacogn Phytother 2011;3:13-26.

12. Tiwari P, Kumar B, Kaur M, Kaur G, Kaur H. Phytochemical screening and extraction: a review. Int Pharm Sci 2011;1;98-106.

13. National Committee for Clinical Laboratory Standards. Performance Standards for Antimicrobial Disk Susceptibility Tests. Fifth Edition: Approved Standard M2-A5. NCCLS, Villanova, PA; 1993a.

14. Kurian S, Josekumar VS. Phytochemical screening, antimicrobial activity and brine shrimp lethality bioassay of different extracts of Alysicarpus vaginalis var. nummularifolius (DC.) MIQ. (family: fabaceae). Int J Pharm Sci 2017;9:1-6.

\section{How to cite this article}

- Uttam Borah, Biswajit Dash, Suvakanta Dash, Juman Deka, Lawrence Kalita. Preliminary phytochemical screening and in vitro antimicrobial activity of ethanolic extract of whole aerial part of the herb Leucas plukenetii spreng (family-laminaceae). Int J Curr Pharm Res 2017;9(3):87-90 